\title{
La experiencia de la salud, la enfermedad y la discapacidad a través de la conciencia corporal
}

José Hoover Vanegas García $•$ José Armando Vidarte Claros 
Esta reflexión consiste en develar los elementos más relevantes de la experiencia de la salud, la enfermedad y la discapacidad a partir de la concepción fenomenológica del cuerpo, el cual se puede ver desde tres dimensiones, el cuerpo vivido, el cuerpo pensado y el cuerpo hablado; categorías de estudio surgidas a partir de los procesos investigativos desarrollados desde el grupo de investigación Cuerpo-Movimiento de la Universidad Autónoma de Manizales.

En este sentido, la experiencia se asume como la manera que tiene el ser humano de relacionarse con el mundo tanto interno como externo. La experiencia como el modo que tienen los seres humanos de asumir el mundo, y en particular la salud, la enfermedad y la discapacidad, como una sedimentación corporal. Se tematiza a partir de la experiencia directa de las personas en coherencia con su existencia corporal en el mundo de la vida, desarrollado en tres puntos de acuerdo con la experiencia de la salud, la enfermedad y la discapacidad tanto del cuerpo objetivo, como el cuerpo subjetivo y el cuerpo intersubjetivo.

\section{LIMITACIÓN DEL PROBLEMA}

La salud solo es tal en la ausencia de la enfermedad, y esta solo es tal en la ausencia de la salud; existe una dinámica entre visibilidad e invisibilidad entre estos dos fenómenos, mientras uno existe el otro se oculta y viceversa. Pero no solo como ausencia, sino como presencia de ausencia, ya que la sola ausencia no genera necesidades puesto que no se puede carecer de lo que nunca se ha tenido, en cambio la presencia de la ausencia de la salud, genera necesidades de ella, es más, en las personas en estado patológico, la salud se convierte en un fantasma que habita en su cuerpo. La enfermedad reclama la salud, y de alguna manera la salud reclama la enfermedad, ya que ella también es fundamental para valorar la salud. La ausencia de cada uno de estos fenómenos convoca a su contrario, como fundamento de cada 
una de ellas. En términos generales el fundamento de la salud es la enfermedad y la base de la enfermedad es la salud.

El escenario original de la experiencia de la salud, y también de la enfermedad, es el cuerpo. La salud, la enfermedad y la discapacidad existen como fenómenos transitivos, que no tienen categorías lingüísticas que las caractericen, ya que su ser está en el depositario de la existencia, en el albergue de la vida en sentido singular, es decir, en el cuerpo: "Dar cuerpo al hombre: esto es lo que hace el análisis anotomofisiológico y el saber biomédico, en sentido amplio cuando separa al hombre de su cuerpo y consideran a este último como algo en sí" (1). No obstante, el cuerpo solo, como un órgano viviente no es suficiente para tematizar la salud-enfermedad, el cuerpo orgánico, Korper como le llama Husserl, como una expresión de la naturaleza que toma la energía liberada y la convierte en energía cinética no es un fenómeno que experimente la díada salud-enfermedad en sentido estricto.

En este escenario corporal la conciencia no es más que el saberse empírico del ser humano; es necesario que el sujeto corporal trascienda este nivel de conciencia y se instale en el saberse a sí mismo como cuerpo de vivencias, como un yo de actos, como cuerpo subjetivo, a lo que Husserl denomina Leib. Sin embargo, la conciencia del cuerpo no termina aquí, hay una dimensión aún mayor del cuerpo y es la conciencia que se reconoce a sí misma en relación con los otros seres humanos encarnada en el cuerpo, que podemos llamar la intersubjetividad o corporalidad.

De esta manera la experiencia de la salud no solo hay que pensarla desde el cuerpo biológico e instrumental sino, desde el cuerpo anímico y desde el cuerpo intersubjetivo. Esta tripartición de las dimensiones del cuerpo, se pueden pensar desde diferentes nominaciones, las cuales se abordarán a continuación: 


\section{El cuerpo vivido y la experiencia de la salud}

Hablar de cuerpo vivido es hablar del cuerpo objetivo, o cuerpo biológico, o cuerpo orgánico. Cualquiera de estas nominaciones brinda la idea de un cuerpo tomado en sus determinaciones físicas, lo que Husserl llama cuerpo cósico $^{1}$, en esta esfera solo interesa la percepción empírica del cuerpo, tanto para sí mismo como para la percepción externa del cuerpo.

Es propio del cuerpo vivido tener experiencias que se acumulan y que determinan, en su ser, en su haber y en su hacer, el modo de presentarse el cuerpo orgánico al mundo de la percepción. Cada una de estas experiencias se ancla en el ser humano y conviven con él, cada una de estas experiencias le da forma al cuerpo mismo. La experiencia, entonces, está enmarcada en cada una de las maneras que tiene el ser humano de relacionarse con el mundo, es una manera de vivencia, y su característica es que no toda vivencia (relación del cuerpo vivo con el mundo) es una experiencia; estas se establecen por la manera en que algunas vivencias quedan en el ser humano, tanto en el cuerpo biológico como a nivel psicológico y a nivel cultural. "En el caso del ser humano, realidad modal constituida por una idea cuyo objeto es un cuerpo existente en acto, el esfuerzo por perseverar puede considerarse solo respecto a la mente o al cuerpo o a la mente y al cuerpo simultáneamente" (2).

La experiencia es un tipo de vivencia que solo es asequible para quien la vive, no pueden haber experiencias testificadas, las experiencias son privadas y más que privadas, íntimas, no salen de la piel del sujeto que las vive, no es posible transferir o comunicar una experiencia en su totalidad, cuando alguien cuenta su propio evento, de la salud, un infarto,

1 Sobre la concepción del cuerpo cósico se puede consultar el libro de Husserl Ideas relativas a una fenomenología pura y una filosofía fenomenológica. Libro tercero. La fenomenología y los fundamentos de la ciencia. Universidad Nacional Autónoma de México. México, lo mismo que el libro El cuerpo a la luz de la fenomenología de Vanegas, 2001. 
por ejemplo, nunca logra perpetrar con las palabras lo que vivió con su cuerpo. La palabra perfecta que muestre una experiencia de la salud no se ha inventado, el lenguaje de las experiencias es inasible. El cuerpo tiene una forma de hacerse saber del sujeto que lo porta que la humanidad no ha podido descifrar. La experiencia se construye entre el cuerpo vivo y el mundo, pero el cuerpo sedimenta estas experiencias de una manera consciente, para darle sentido al mundo.

La experiencia, como la voz alemana lo revela, es Erfahren, de donde Fahren significa andar, y la voz Er significa perseverar, insistir, de tal manera que la experiencia es andar con un propósito claro, es decir, con intencionalidad (3).

La experiencia "llegar al fin del fahren, o sea, conseguir algo en ese fahren, alcanzar algo en el sentido puramente espacial o también recorrer una región". De esta manera la experiencia exige estar en la escena, vivir el escenario, con el propio cuerpo; de aquí que la experiencia implique conocimiento: "De allí surge el sentido figurado de «erfahren» como tomar conocimiento de algo por haber tomado contacto con eso a través del «fahren», en el «fahrt» (viaje)" (4).

La experiencia de la salud a través del cuerpo vivido, es una huella que marca la existencia de cualquier ser humano; el conjunto de experiencia fundamenta la normalidad del cuerpo y por consiguiente de aquí surge lo anormal, lo patológico: "Toda concepción de patología tiene que apoyarse sobre un conocimiento previo del estado normal respectivo" (5).

El cuerpo coexiste sedimentado de experiencias, estas se conforman como hábitos, y estos se expresan al mundo de la percepción por medio de acciones. Cuando hay coherencia entre estos tres elementos no hay problema para los sujetos corporales, pues la regularidad genera lo normal, mien- 
tras que la eventualidad, las desarmonías. Las vivencias de lo normal no marcan la vida del sujeto, precisamente por ser regulares, mientras que lo anormal, y con ello las patologías por ser eventuales, se constituyen como experiencias en el trasegar de la vida del sujeto corporal. La experiencia de la salud del cuerpo solo se encuentra en la enfermedad, esta es la que le da sentido y significado a la salud, puesto que la experiencia de lo patológico marca la vida de la humanidad.

En este sentido, la experiencia sobre la salud es íntima, es solo de quien la vive, en la experiencia de la salud el cuerpo habla, el cuerpo se le revela al sujeto, el cuerpo interroga, rompe el silencio que genera lo normal, la eventualidad hace visible el cuerpo, por ello es que Cangilhen citando al cirujano Leriche, afirma que "la salud es la vida en el silencio de los órganos". En la vida corporal de la salud el cuerpo vive referenciado al mundo, vive enajenado de sí mismo, vive en el mundo de lo otro: "Estoy sano cuando estoy volcado a mis actividades, relaciones, placeres, sin tener que escuchar a mi cuerpo, sin tener que atenderme" (6). La salud habita silenciosamente en el cuerpo material, la salud invisibiliza el cuerpo para su portador, la enfermedad es un fantasma oculto en los escondrijos del cuerpo.

En algunos momentos estos fantasmas cobran realidad física y se manifiestan al sujeto generalmente en forma de dolor, su presencia le anuncia al sujeto la existencia del cuerpo alterado. El dolor es la voz de la enfermedad, es la manera como el cuerpo interroga al yo, entonces, el sujeto debe volcarse sobre su propio ser corporal, debe volver sobre su propia carne, en la enfermedad algo nuevo aparece, en el sujeto algo ha irrumpido la regularidad del ser humano: "La iniciativa para cualquier teoría ontológica de la enfermedad hay que atribuirla a la necesidad terapéutica. Ya significa tranquilizarse, en parte, considerar a todo enfermo como un hombre al cual le ha agregado o quitado un ser. Aquello que el hombre ha perdido, puede serle restituido, aquello que ha entrado en él, puede salir de él” (5). 
La experiencia del cuerpo enfermo es más fuerte para la conciencia entre más próxima sea, con el tiempo se va desvaneciendo hasta llegar a lo más hondo del pasado en donde se mezcla con el silencio de la salud y entra al mundo del olvido, se hace fantasma. Los recuerdos de las experiencias del cuerpo enfermo no duelen. En la experiencia de la salud y la enfermedad entra a jugar un papel fundamental la conciencia corporal, la cual puede asumirse, como: “...la total consistencia fenomenológica real del yo empírico, como el entrelazamiento de las vivencias psíquicas en la unidad de su curso" (7).

La conciencia empírica implica el volver del sujeto sobre su ser material, es decir, es el autorreconocimiento que el sujeto hace de sí mismo como un objeto en el mundo de lo percibido, como se mencionó anteriormente, un cuerpo fáctico con una colección de experiencias físicas. En este sentido los deslizamientos de la salud a la enfermedad acaecen inicial y fundamentalmente en el cuerpo orgánico y por ende en lo fisiológico, el cuerpo que le habla al sujeto y sus alteraciones tiene su fundamento en toda su existencia corporal.

El ser humano inicial y fundamentalmente es cuerpo-materia, es imposible escapar a la condición cósica a la cual se está expuesto, por esto: "Las cualidades de los hombres se deducen de las apariencias de su rostro o de las formas de su cuerpo, se lo percibe como una emanación moral que no puede escapar de su apariencia física" (8). La experiencia patológica se condensa en la atención de la materia del cuerpo y sus funciones. La experiencia del cuerpo atravesada por la conciencia de la patología regresa al sujeto a su condición primaria, lo hunde en lo más profundo de su realidad material, le hace caer en la cuenta que su existencia depende de su materialidad y su "buen" funcionamiento, lo regresa a sus propias carnes, a su estómago si son problemas gástricos, a su corazón si son alteraciones 
cardíacas, a sus pulmones si son problemas respiratorios, etc. "Sólo la conciencia, la vida mental y sus actos -y no el cuerpo en cuanto tal- son la llave que da acceso y explicación cabal a la realidad" (9).

La experiencia de la enfermedad, no solo genera conciencia de la corporalidad material, sino que despresa al ser humano, cual ave de corto vuelo lista para la cena de los médicos. Este des-presamiento también es posible develarlo en las especializaciones de las ciencias biomédicas, con solo evocar los nombres y ya desmembramos a los seres humanos: especialización en mano, en gastroenteritis, neurología, especialización en pie, ortopedia, salud oral, fonoaudiología, optometría, entre otras. La evolución científica reduce la extensión para ganar comprensión, pero en este proceso fractura la existencia integral del ser humano, lo suma a sus partes: "Más allá de los caprichos del deseo y las exigencias del alma, el cuerpo se encuentra además agitado por sensaciones y aflicciones que brotan de sus "profundidades", esto es, de un interior oscuro y misterioso capaz de contaminar la mente e influir sobre las relaciones de las personas, con el mundo exterior" (9).

En la experiencia de la vida cotidiana el cuerpo se hace invisible, el cuerpo solo cobra existencia cuando aparece un fenómeno in-habitual, por esto las patologías visibilizan el cuerpo material. Esta relación entre el yo que habita en cada pensamiento se dirige al cuerpo material, es la relación experiencial en el enfrentamiento inevitable de una enfermedad, la impotencia del sujeto frente a la fuerza o el poder que ejerce la enfermedad a través del cuerpo, hace que aparezcan en la escena de la experiencia patológica los profesionales de la salud, cuando no un chamán, un hechicero. La existencia de los médicos solo es posible como producto de la impotencia del ser humano cuando enfrenta una experiencia corporal de una enfermedad, por esto la medicina es "una técnica terapéutica situada en la encrucijada de muchas ciencias" (5). 
De esta manera la experiencia del profesional de la salud es diferente a la experiencia del sujeto portador de la enfermedad, la mirada del profesional escinde el ser humano de su propio cuerpo, lo cual es lógico en la profesión liberal y positivista, regularizada; la particularidad del cuerpo y de los sujetos para los profesionales no existe, ya que la fisiología se basa en la regularidad, y no puede ser de otra manera, ya que esta es la que genera las posibilidades científicas. Para las ciencias médicas, el fundamento epistemológico es la normalidad, la salud, la enfermedad es una eventualidad, que emerge de los azares de la vida; en este sentido, los profesionales de la salud tienen su propia experiencia frente a la enfermedad testificada, no vivida.

El discurso médico biológico enfrenta el fenómeno que reduce al sujeto a su condición corporal desde la ciencia y esta se reduce a la positividad de la misma: "La presencia de la enfermedad en el cuerpo, sus tensiones, sus quemaduras, el mundo sordo de las entrañas, todo el revés negro del cuerpo que tapiza largos sueños sin ojos, son, a la vez, discutidos en su objetividad por el discurso reductor del profesional y fundados como tantos objetos por su mirada positiva" (10). Bien, pero la experiencia de los sacerdotes de la salud es una tarea diferente.

La experiencia, en sentido corporal, de la enfermedad, es una vivencia que no sale de la piel de quien la siente, pero toda experiencia tiene un tiempo y espacio, que para el caso son dos condiciones corporales, determinantes de la materia, son dos características objetuales al igual que el cuerpo físico: "Entonces, para un sujeto solipsista solamente tiene sentido hablar de una corporalidad patológica, que funciona anómalamente, si tiene su sistema de experiencias ortoestéticas y con él constantemente frente a si la naturaleza espacio-temporal-causal una" (11). 
El tiempo de la experiencia patológica excluye, aunque no de una manera absoluta, los eventos del pasado y las propensiones del futuro del cuerpo, ya que la vivencia por su condición de alteración de la armonía todo o casi todo se centra en el instante presente, mas cuando hay dolor, pero el tiempo del ahora vivido, no es proporcional al tiempo del reloj o del cronómetro, este es un tiempo infinito, es una pausa en el presente corporal que no tiene bordes, no tiene límites. De un lado y de una manera fantasmal la muerte llama o hala ese presente interminable y del otro, la ausencia de la presencia de la vida se insinúa como resistencia al cuerpo material. El tiempo de la experiencia del cuerpo material frente a la enfermedad es un tiempo subjetivo, que a pesar de los diagnósticos de especialistas es gaseoso para quien lo vive, e incomunicable para el que lo padece, e inefable para quien lo testifica.

En cuanto al espacio de la experiencia patológica, al igual que la temporalidad, está marcada por la geometrización topográfica del mundo, un cuarto de una clínica o un hospital, una cama o una camilla, son los sitios que limitan la experiencia, pero estos lugares más que lugares con medidas determinadas, se constituyen en la experiencia como escenarios vivenciales; en algunos casos, cuando no en todos, son espacios que obstaculizan la vida cotidiana, y como consecuencia la vida misma el espacio se hace prisión, entonces además de la experiencia de la patología también es una experiencia de la limitación espacial. La cama deja de ser un lugar de placer para ser una tortura, una máquina que amplifica el dolor, el cuerpo se extiende hasta la cama y luego a la habitación, el cuerpo no se encuentra en la cama, esta es una enemiga de la extensión del cuerpo material y el hospital o la clínica, una cárcel imposible de soportar, imposible de saltar.

El cuerpo deja de ser una parte del cosmos y pasa a ser un cuerpo ajeno al que no le corresponde vivir en prisión: "El cuerpo se asimila a un campo 
de fuerzas en resonancia con los procesos vitales que lo rodean. En las tradiciones populares el cuerpo está unido al mundo, es una parcela inseparable del universo que le proporciona su energía. Es una condensación del cosmos" (12).

El dolor, como se mencionó anteriormente, es la manera como el cuerpo le anuncia al sujeto sobre su desarmonía. La experiencia algológica es quizá, la más tenebrosa del ser humano frente a la enfermedad, solo se está enfermo si algo nos duele, de tal manera que el dolor evoca la naturaleza humana de su situación corporal finita, limitada frente a las posibilidades del mundo: "El dolor no es la fidedigna transmisión de una señal generada por un estímulo nocivo (nocipercepción), sino que es más bien una percepción compleja influenciada por la naturaleza de la situación, en la cual el estímulo se experimenta, la experiencia previa y las emociones" (13).

Ahora bien, el dolor solo se da en el cuerpo material, en el cuerpo cósico, el cual reduce al ser humano a su condición objetual, el dolor hace que el sujeto vuelva su atención sobre su carne, sobre su ser material en el mundo de la vida. El dolor es una sensación que solo puede vivir quien lo padece, tampoco es transmisible: "la existencia del dolor solo puede ser reconocida por quien lo posee. Esto es, mi dolor es solo mío y nadie puede sentir mi dolor como yo lo siento" (14).

Hasta aquí se genera la experiencia de la salud vista a la luz de la corporalidad material o cósica. Es necesario advertir que la experiencia sobre la salud no se limita en el cuerpo en sentido físico, el sujeto además transciende los límites de su propia carne ya que la particularización del cuerpo solo tiene realidad en la teoría, no en la práctica. El sujeto también es un ser psicológico que tiene sus principios vivenciales y en ellos se fundamenta la experiencia anímica, la cual intentamos tematizar a continuación. 


\section{La experiencia anímica entre salud/enfermedad}

El cuerpo enfermo provoca en el sujeto paciente (o usuario, como se dice en la actualidad) la aparición un cuerpo fantasmagórico, de tal manera que la experiencia somatológica de la enfermedad genera la ilusión de la existencia de otro cuerpo, diferente al cuerpo saludable, idealizado que todo ser humano cree que tiene. "Un enfermo siente en su cuerpo a una segunda persona implantada. Es un hombre en una mitad de su cuerpo, (...) ¿Cómo distinguir en un síntoma las causas fisiológicas y los motivos psicológicos? ¿Cómo asociar simplemente las dos explicaciones y cómo concebir un punto de conexión entre los dos determinantes?" (15).

El ser humano más que cuerpo material es un ser vivo, anímico, que además de enfrentar la enfermedad, se sabe a sí mismo como un ser enfermo. Este saberse a sí mismo como un sujeto de vivencia muestra un concepto de conciencia más evolucionado; para este caso, la conciencia deja de ser la atención sobre el cuerpo material y ahora es la atención al ser de vivencias o de acciones psíquicas, como lo llama el creador de la fenomenología: "La conciencia como percepción interna de las vivencias psíquicas" (16).

De esta manera el sujeto no solo existe en el mundo, se sabe existiendo, y se siente sentido, como lo afirma Merleau-Ponty 1984: 16: "El enigma reside en que mi cuerpo es a la vez vidente y visible. Él, que mira todas las cosas, también se puede mirar y reconocer entonces en lo que ve el "otro lado" de su potencia vidente. Él se ve viendo, se toca tocando, es visible y sensible para sí mismo" (17).

Bajo este panorama, la experiencia anímica de la enfermedad trasciende la experiencia patológica del cuerpo material. Ahora se plantea la manera como el sujeto se constituye a sí mismo, como ser "psicológico". El cuerpo material se oculta, pero no desaparece, su latencia persiste en el equilibro 
salud/enfermedad, en el límite entre lo "normal" y lo "anormal" pero la experiencia patológica se centra ahora en el ánimo sobre lo cual afirma el filósofo somático francés, en forma de metáfora: "mejor será decir que el cuerpo sentido y el cuerpo sintiente son como el reverso y el anverso o como dos segmentos de un solo recorrido circular que, por arriba va de izquierda a derecha, y por debajo, de derecha a izquierda, pero solo constituye un movimiento único en sus fases" (18). En este terreno, la experiencia hay que cincelarla en el cuerpo enfermo representado en la mente, en la imagen que el sujeto tiene de sí mismo, en el cuerpo pensado. La relación experiencial, entonces, se da entre el yo sujeto y la concepción que él tiene de su cuerpo. En las experiencias anímicas la urdimbre es el hombre, no solo su cuerpo.

La experiencia patológica del hombre constituye un deslizamiento entre la vida y la muerte; la enfermedad le recuerda al ser humano su condición finita, su vulnerabilidad frente a la infinitud del mundo. El ser humano, como individuo en la naturaleza, no es más que un eslabón en el tiempo y la enfermedad es la notificación de esta tesis: "El otro, como carne, como cuerpo cósico entra y sale de la existencia del cuerpo propio de una forma continua, es más, el otro nunca puede ser permanente a nuestra transcurrencia de instantes, el otro ajeno no es más que una intermitencia en nuestra existencia, solo la corporeidad sigue habitando en el cuerpo propio" (19). En este sentido, ningún ser humano es para siempre, por lo menos como cuerpo presente, aunque su recuerdo puede perdurar, su existencia se extingue del mundo; la enfermedad es la manera como el cuerpo le balbucea al oído del ser humano que su existencia no es para siempre: "Todo cuerpo es un trozo de naturaleza, es un pedazo de mundo, pero en el caso de los cuerpos humanos estos se alejan de la naturaleza y del mundo mismo; hacerse humano, consistía y consiste en cobrar distancia de la naturaleza y del mundo" (20). 
La experiencia humana de la enfermedad implica reconocerla como una entidad, ontológica y como un mecanismo de la naturaleza que el cuerpo biológico desarrolla para curarse: "La enfermedad no solo es desequilibrio o desarmonía, también es -y puede ser principalmente- esfuerzo de la naturaleza en el hombre para obtener un nuevo equilibrio. La enfermedad es una reacción generalizada con intenciones de curación. El organismo desarrolla una enfermedad para curarse" (5). De esta manera, la lucha del ser humano por extinguir la enfermedad, no es una lucha honesta, ya que el enfrentamiento es con la condición inerme del ser humano frente al mundo, la enfermedad en sí misma es un mecanismo de defensa, es una manera de proteger la vida: "Las enfermedades solo son los efectos de meros cambios de intensidad en la acción de los estímulos indispensables para el mantenimiento de la salud" (5).

Frente a la enfermedad aparece la experiencia del miedo, el rostro que genera el miedo es inevitable, no hay actor que supere el impulso gestual que brota del ser humano cuando se enfrenta a la enfermedad. El miedo que genera la enfermedad tiene su fundamento en el enfrentamiento con lo desconocido que puede generar el estado patológico. Lo que no es descifrable, con certeza, pero solo en el lado oscuro ya que los síntomas le dicen al enfermo de su malestar, de su sufrimiento, de su dolor.

Quizá una de las escenas de la vida en donde más se evidencia la separación de la imaginación de la enfermedad misma acaecida en el cuerpo material, es la hipocondría, aquí la imaginación es más poderosa que la perturbación corporal; de hecho, la imaginación genera la enfermedad, que existe solo como un elemento fantasma en la mente humana, y se traslada al cuerpo mismo, de forma similar la anosognosia (miembro fantasma) o el miembro con voluntad propia: "Así se delimitan en el conjunto de mi cuerpo unas regiones de silencio" (15). Estas son patologías que tienen 
su origen, más en la mente que en el cuerpo, pero la patología misma se desliza de su existencia pensada a la existencia sentida. En la experiencia patológica del sujeto anímico la importancia aparece en el sujeto de sentidos y no solo en el cuerpo físico, ya que detrás de cada enfermedad siempre hay un ser humano: "¿Acaso el cuerpo no es considerado bajo el velo de sus representaciones? El cuerpo no es una naturaleza. Ni siquiera existe. Nunca se vio un cuerpo: se ven hombres y mujeres" (12).

La experiencia de las enfermedades se pueden caracterizar de acuerdo a la manera como ellas se revelan al sujeto que las vive: entre más fuerte sea el estímulo que sale del cuerpo físico y se instala en la consciencia psíquica, más poderosa es la enfermedad, entre menos fuerte sea el estímulo y menos el impacto en la sensación, menor es la enfermedad. Para la experiencia humana importa poco el conocimiento científico de la patología y de la fisiología, solo importa la sensación de la enfermedad y el dominio que sobre ella se ejerce. La experiencia patológica, no solo debe tratar el cuerpo independiente del hombre, debe considerar que la enfermedad no es de la carne sino del ser humano: "La medicina, al desterrar al hombre que se encuentra al final de su camino, se expone a reencontrarlo como un cuestionamiento de sus fundamentos. La medicina es la medicina del cuerpo, no la del hombre" (21).

¿Cómo categorizar la enfermedad experienciada? Esta es una tarea que hay que pensar. Lo que sí es claro, es que está lejos de las taxonomías de las ciencias médicas. El sentimiento de enfermedad despierta en el ser humano todo su trasfondo, todo su lado oscuro, el sentimiento golpea muy duro en el alma, de allí brotan todos los sufrimientos, de allí emergen todas las perturbaciones que trascienden el dolor mismo, puesto que este es del cuerpo, mientras que el primero es del alma. El dilema se da aquí entre la razón y el sentimiento: “Ante todo, parece poco claro dónde principia y 
dónde termina el dominio del cuerpo, el de la razón o el de las emociones. Su imbricación es tal que se diría que en este vasto sentir reposa la esencia ontológica contemporánea y que a su perfeccionamiento se han dado los discursos sensoriales fundados en un "trabajo corporal" diseñado para asumir un compromiso con nuestro cuerpo" (22).

Ascender en las consideraciones de las experiencias en salud de la condición fáctica a la condición espiritual significa trascender de las consideraciones del dolor e instalarnos en las emergencias que genera el sufrimiento. Este deslizamiento del dolor al sufrimiento es proporcional al tránsito de la transferencia del cuerpo físico al cuerpo animado o, lo que es lo mismo, de la carne al ánimo, por esto el dolor se puede localizar, alumbra en lugares determinados del cuerpo, en cambio el sufrimiento no tiene una taxonomía corporal, puesto que este se ilumina en toda la geometría del cuerpo: "Es muy curioso. De repente veo en mi interior... distingo las profundidades de las capas de mi carne y siento zonas de dolor, anillo, polos, penachos de dolor, ¿ve esas figuras vivas?, ¿esa geometría de mi sufrimiento? Hay relámpagos que se asemejan por completo a ideas" (23).

El sufrimiento es un tipo de perturbación del alma, que sale de la latencia a la evidencia como producto de algunos momentos en donde el ser humano se siente impotente, en donde su razón no puede responder las preguntas indescifrables que el cuerpo le lanza a la conciencia, en donde el sentimiento experienciado es más fuerte que cualquier medicamento o terapia tecno-médica. La potencia del ánimo se reduce a su mínima expresión. El sujeto queda diezmado por la incapacidad de interferir en su propio cuerpo, el ser humano lleva en su propia naturaleza su formación y su cuidado, como afirma Foucault (9): "Formarse y cuidarse son actividades solidarias". La esfera de lo anímico alberga el sufrimiento, mientras que la dimensión de la física u orgánico alberga el dolor, el iatrólogo se encarga de 
este, pero ¿quién se encarga del sufrimiento?. Claro que aliviar el cuerpo es un paso importante, como afirma Onfray: "Hay que dar al cuerpo lo que es del cuerpo para que el alma permanezca en la tranquilidad y se bañe en la serenidad: he aquí el credo de los materialistas de la antigüedad -y de sus seguidores- una dietética de las pasiones, de los deseos y de los placeres permite un trato apaciguado con el mundo" (24).

El tiempo y el espacio de la experiencia patológica a partir del ser anímico también cambia, ahora hay que mirar el tiempo, desde la manera como trasncurren los instantes en el pensamiento en coherencia con los estados de ánimo. En este sentido, el tiempo del sufrimiento no es posible medirlo ya que está determinado por la subjetividad del enfermo; la experiencia del tiempo para las personas en situación de enfermedad no acontece como numeración de instantes, sino como pausas -en el presente- infinitas e interminables y en esta pausa del ahora vivido se aúna todo lo que se quiere vivir y todo lo que se ha vivido: "La corporeidad es una idea implícita en la conciencia atravesada por la retención y la propensión, es decir, es una impresión que está en constante fluir entre lo que la conciencia conserva de todo lo que el cuerpo ha sido o soñado, tanto desde el cuerpo orgánico, como desde el cuerpo animado y todo lo que se quiere o espera ser corporalmente, igualmente tanto desde lo físico como desde lo subjetivo" $(25,26)$.

Esta misma reflexión se aplica al espacio, en tanto maneras de habitar un escenario. El habitar, ya implica atravesar el sitio geográficamente determinado por la subjetividad; el lugar mismo en donde el sujeto se habita se constituye en la manera de ser de la persona en situación de enfermedad, el ser mismo es un pedazo de universo, un trozo de cosmos, que cabe en el mundo. Cuando aparece la experiencia de la patología ella le advierte al ser humano que su existencia desborda su ubicación en el espacio, "que 
sobra en el mundo". El cuerpo se hace espacio a partir de la temporalidad misma, como afirma Jaramillo (27) "El cuerpo es a la vez disponibilidad y disposición, conciencia de un algo inmediatamente vivido y memoria de un futuro que se anticipa. No soy porque tengo un cuerpo, sino que es en el sentirme a mí mismo y desde el proyectarse de mi cuerpo que se estructura el mundo espacial que habito que, en cuanto tal constituye el eje de todas mis acciones".

\section{La experiencia del cuerpo enfermo a través de la cultura}

La tensión entre la salud y la enfermedad en la cual consiste la experiencia del ser humano en la mayoría de su vida, transita de su condición corporal física a su condición anímica o "psicológica" y de esta al mundo social y cultural. El ser humano se individualiza en su cuerpo como hecho objeto en el mundo de la vida, pero también como subjetividad, como sujeto de vivencias, pero además de esto se relaciona con otros sujetos, no vive solo, vive en comunidad; así las guerras demuestren la insociabilidad humana, el sujeto siempre necesita de los otros. Es más, nuestra identidad solo se construye en relación con los otros; lo mismo sucede con la experiencia de la salud y la enfermedad. Ella cobra forma en la relación con los otros y con el mundo simbólico: "El hombre no es el producto de su cuerpo, él mismo produce las cualidades de su cuerpo en su interacción con los otros y en su inmersión en el campo simbólico" (8).

La experiencia de las "personas" frente a la enfermedad exige la comunión con los otros, y a la vez el conjunto de significados que la humanidad ha construido en el devenir histórico, es decir, el mundo simbólico. En un primer sentido la experiencia se edifica a partir de la imagen que tienen los seres humanos tanto de la enfermedad como del cuerpo, de la muerte, y aún de los iatrólogos. La imagen es previa a cualquier experiencia, esta coexiste en el sujeto y luego se le pone a las experiencias; 
de hecho, nuestro cuerpo además de ser experienciado en cada momento también es construido como imagen, y esto solo es posible en la medida en que el cuerpo siempre está teniendo experiencias: "El cuerpo enfrenta siempre las mismas experiencias, como tiempo, espacio y muerte, que ya se han captado a priori en imagen" (2), las imágenes de las realidades son construidas en comunidad, el sujeto se enfrenta al mundo en coherencia con la imagen de sí mismo y de los otros: "La conciencia vista desde la experiencia individual, corporal, se visibiliza y se invisibiliza de una manera continua, pues no siempre la tenemos encendida, pero tampoco permanece apagada constantemente, ya que existe una dinámica entre la conciencia activa y la conciencia pasiva" (28).

A pesar del aislamiento de las personas, la mirada da muestras de atisbos del ser de los otros, de la existencia y, por tanto, del conjunto de experiencias, entre ellas la enfermedad y la salud. En este sentido advierte Husserl $(17,14)$ : "La mirada que experimenta teóricamente capta con facilidad en lo percibido notas dadas a través de la percepción, en la medida en que se es consciente de algo real, se es también consciente de nexos causales, aunque de modo completamente oscuro y sólo susceptible de definir y precisar mediante el análisis y la investigación teóricos de la experiencia" (26).

En este escenario la experiencia de la enfermedad se puede develar a través de la mirada, en la mirada se des-cubre el sufrimiento que la experiencia del dolor marca en las personas, en la mirada se revela la conciencia experienciada de los otros, en la mirada se descubre la sombra de la muerte: "Lo patético del dolor no consiste solo en la imposibilidad de huir del existir, en el hecho de estar acorralado, sino en el terror a abandonar esta situación de luz cuya trascendencia nos anuncia la muerte" (27). La mirada y en general el rostro del enfermo no oculta el dolor, no puede ocultar el 
sufrimiento, el rostro es la faz del alma, allí se encuentra toda la historia y toda la espera, allí se encuentra el arsenal de sufrimientos y las esperanzas del cuerpo enfermo.

El rostro es lo visible del cuerpo, y por visible es la expresión de las creencias, de los conocimientos, de los valores, y por supuesto de los sentimientos y entre ellos el sufrimiento, el dolor se asoma por el rostro de las personas en situación de experiencia de enfermedad; en este sentido el rostro debe tomar el lugar del cuerpo, debe volver sobre el cuerpo mismo ya que es el puente entre la intimidad de la subjetividad y los otros, el rosto es lo púbico del sujeto: "Hace falta que el cuerpo se someta al rostro, que se deforme, se aplane para dejar de representar un obstáculo a la difusión de la luz y a la reflexión en un rostro que lo domina pero que ya no parece pertenecerle, pues si el cuerpo no es más que un pálido reflejo de la procesión del ser, el rostro disfruta de otra dignidad, porque expresa la convención del alma humana a su propia causa, es decir, porque se desencarna" (9).

La experiencia humana de la salud pone en juego el pudor, el ser humano queda reducido a su cuerpo físico; detrás de un cuerpo enfermo siempre encontramos a una persona, encontramos un ser humano igual a los otros. Quizá una de las experiencias más fuertes es la mirada que genera a quienes testifican su condición miserable, ¡cómo está de flaco!, ¡cómo está de pálido!, ¡Cómo se mueve!, son expresiones muy frecuentes de los dolientes, y esto hace que el ánimo del sujeto se reduzca, la enfermedad ideológicamente carga con un significado negativo, esto hace que la experiencia patológica del sujeto se convierta en una experiencia maléfica, esto hace que la enfermedad esté llena de maldiciones. ¿Será qué puede haber otra manera de entender la enfermedad?

Frente a esto, "La patología, sólo es una rama, una consecuencia, un complemento de la fisiología, o más bien, esta abarca el estudio de las ac- 
ciones vitales en todas las épocas de la existencia de los cuerpos vivos" (5). Nuestra cultura niega la enfermedad, por esto la experiencia sobre la misma es un acontecimiento trágico, que ciega a la humanidad frente a la vida misma, la salud no puede existir sino como acaecimiento de lo patológico: "El comportamiento patológico debe comprenderse por sustracción a partir del comportamiento normal, se trata a la enfermedad como simple déficit o, en todo caso, como un fenómeno negativo; se quiere que no haya verdaderamente acontecer en el organismo" (18).

Así como la dinámica entre la salud y la enfermedad, lo normal y lo anormal, lo regular y lo eventual, el ser humano en la experiencia de la salud mantiene en el límite; mantiene en el borde de uno y de otro y esto se expresa en la indescifrabilidad del cuerpo, el cuerpo es la sede de este fluir, en él se condensan todas estas paradojas: "El cuerpo (humano) es pensado -y construido- en virtud de esta oscilación que lo lleva de lo luminoso a lo sombrío, de la belleza a la fealdad, de la valentía a la cobardía -el cuerpo es esta oscilación, esta división" (29).

El padecimiento fundamental que singulariza la experiencia personal de la patología es la angustia, la angustia es la sedimentación del dolor y del sufrimiento en el espíritu humano. El sentimiento de la angustia se traduce como la conciencia de la ausencia de alternativas en la vida cotidiana. Imposibilidad de movimiento, como en algunas situaciones de discapacidad, soportar el dolor, como en algunas enfermedades crónicas, la reducción en la relación con otros, como en algunas patologías de carácter transmisibles, entre otras.

La angustia se genera cuando el ser humano ve su futuro oscuro, cuando la estrechez del mundo lo asfixia y lo deja sin ninguna salida, la angustia es la conciencia de la nada del ser en su particularidad: "La angustia singulariza al "ser ahí" en su más peculiar "ser en el mundo" que en cuanto com- 
prensión se proyecta esencialmente sobre posibilidades" (30). La angustia, como característica de la experiencia del ser humano espiritual frente a la enfermedad reduce la libertad de la cual afirma el mismo filósofo: "La apertura del comportamiento como posibilidad interna de la exactitud se funda en la libertad. La esencia de la verdad es la libertad" (30).

Entre más se reduce la libertad más aumenta la angustia, ya que la libertad es una colección de alternativas en el mundo de la vida mientras que la angustia es la ausencia de posibilidades; en este sentido la ausencia de libertad sume a las personas en la soledad absoluta: "La angustia singulariza y abre así el "ser ahí" como "solusipse" (30). El ser humano es en la medida en que cada día sea más, el ser humano no es un ser terminado sino un ser inconcluso que todos los días tiene que velar por su propio ser. Cuando estas posibilidades se ven oscurecidas, el hombre se ve en una caída constante a la nada absoluta: "El temor es angustia, caída en el "mundo" impropia y oculta, como angustia para sí mismo" (30). La enfermedad reduce la libertad, reduce el ser, por ello genera angustia porque la patología enuncia la muerte, el riesgo. En coherencia con esto, en algunos seres humanos, la muerte es la única solución: "En el riesgo, al aceptar la muerte. La voluntad encuentra su total independencia. Quien ha aceptado la muerte se resiste hasta el límite a una voluntad extraña. A menos que el otro quiera también esta muerte. La aceptación de la muerte no permite, pues, resistir con seguridad a la voluntad homicida del otro" (28).

Ser persona es un proyecto, en donde el sujeto tiene la libertad de volver sobre sí mismo para ajustar constantemente sus actos con el fin de prolongarse en su ser, el sujeto es dueño de su propia existencia: "Cualquiera que sea el obstáculo que la existencia ofrece al existente y la importancia del existente, el existente es dueño de su existencia" (28). Sin embargo, su vida se mantiene expuesta al mundo de las alteraciones, de las desarmonías, las 
cuales, en últimas generan patologías, el ser corporal en el mundo vive entre lo bueno y lo malo de una manera natural. De esta manera el sujeto se vuelca sobre sí mismo para suprimirse de cosas, de actos que pueden alterar la vida, no obstante el sujeto está atado a su propia libertad: "Pero esta libertad es algo más que una no esclavitud, más que una manumisión que hiciera al individuo independiente de toda constricción exterior o interior; en su forma plena y positiva, es un poder que ejercemos sobre nosotros mismos en el poder que ejercemos sobre los demás" (10). Así la libertad se fundamenta en la experiencia de la voluntad, pero esta depende en gran medida de las condiciones o las situaciones, no son solo decisiones individuales sino condicionales de existencia: "La limitación de la voluntad no es interior (La voluntad en el hombre tan infinita como en Dios), no reside en el querer de la voluntad sino en su situación" (28).

La experiencia patológica de las personas en el ámbito cultural le da el valor a la enfermedad de algo malo, el mal se apodera de la vida humana, genera sufrimiento: "En rigor, el mal no puede describirse mediante la pasividad, sino que el padecer se comprende a partir del mal. El sufrimiento es un puro padecer" (28). De esta manera, la enfermedad es un mal que asoma en los cuerpos que alumbra el sufrimiento, estanca la vida: "Todo mal remite al sufrimiento. Es el estancamiento de la vida y del ser, su absurdo, el lugar en donde el dolor no viene a "colorear" afectivamente -y en cierto modo inocentemente- la conciencia. El mal del dolor, su malestar, es como el estallido y la articulación más profunda del absurdo”. El dolor, el sufrimiento cargan con una colección de hábitos que migran de generación en generación con el nombre del mal, cuando la enfermedad por sí misma hay que tratarla y vivirla como un proceso enmarcado entre los parámetros normales del mundo de la vida: "La enfermedad difiere del estado de salud, lo patológico de lo normal, como una cualidad difiere de otra, ya sea por presencia o ausencia de un principio definido, ya sea por reelaboración de la totalidad orgánica" (6). 
La experiencia de lo patológico a partir de la libertad, el dolor, el sufrimiento y la angustia no es posible pensarla en el sujeto sin pasado, el ser humano es histórico: "El cuerpo -y todo lo que se relacione con el cuerpo, la alimentación, el clima, el sol- es el lugar de la Herkunft: sobre el cuerpo se encuentra el estigma de los sucesos pasados, de él nacen los deseos, los fallecimientos y los errores; de él se entrelazan y de pronto se expresan, pero también en él se destacan, entran en lucha, se borran unos a otros y continúa su inagotable conflicto" (10).

En cada presencia corporal de las personas resplandecen posibilidades infinitas de lecturas, de acontecimientos que se revelan en el rostro del sujeto y no lo es menos cuando nos referimos a la colección de experiencias patológicas. La cultura genera ritos que se anclan en el cuerpo, y estos a su vez conservan la historia, el cuerpo en sí mismo conserva lo ritual y lo histórico: "El rito habla del cuerpo, pero también... el propio cuerpo habla de su historia (31). De esta manera, la presencia en el ahora del cuerpo activa un sistema comunicacional, todo cuerpo es una o muchas expresiones que esperan ser leídas, que esperan ser comunicadas; el cuerpo es a la mente lo que la palabra es al pensamiento: "El hombre, como cuerpo en el mundo, es expresión, puesto que cada vivencia lleva una intención de acuerdo con la motivación, la cual es el propósito de quien vive la vivencia en el co-estar con los otros" (21).

\section{LA DISCAPACIDAD COMO VIVENCIA CORPORAL}

El abordaje de la discapacidad está condicionado por la perspectiva o el prisma que se use para comprenderla, en la mayoría de los casos esta perspectiva tiene variaciones en cada campo disciplinar y es diferencial cuando se habla de ella como vivencia particular o colectiva. Por esta razón intentaremos hacer una aproximación desde diferentes miradas a la categoría de discapacidad para posteriormente proponer las perspectivas que desde el 
cuerpo se expresan en la vivencia. En la perspectiva de las personas con discapacidad se podría afirmar que estos sujetos han sido receptores de una cantidad de respuestas discriminantes por parte de la sociedad, las cuales se describen especialmente desde la tendencia de inferioridad biológica o fisiológica que imponen una presunción de incapacidad extrapolable a las dimensiones sociales y políticas (32).

La inferioridad biológica y fisiológica se relaciona con nociones como insuficiencia, déficit e invalidez y atiende a razones puramente médicas. La insuficiencia hace referencia a la alteración en la organización funcional del organismo que implica el no cumplimiento de un proceso fisiológico, mientras el déficit hace referencia a la alteración funcional que implica un desempeño por debajo de lo que se considera normal, y la invalidez tiene la connotación de la incapacidad para realizar una actividad o ejecutar un rol. Es decir, el concepto de invalidez se asume en muchos casos como un factor negativo y finalmente son estas tres acepciones las que históricamente han marcado el imaginario colectivo que da sentido a las concepciones de deficiencia, la discapacidad y la minusvalía en la perspectiva que planteó la OMS (33).

En el ámbito contextual la persona con discapacidad enfrenta diferentes formas de exclusión con restricciones económicas, sociales, culturales, entre otras. En este sentido la categoría de discapacidad ha estado definida por la interacción permanente entre el poder, la marginación y la dependencia. Estas condiciones de marginación y dependencia sustentan que las personas con discapacidad necesitan ayudas especiales para poder integrarse de una forma normal en la sociedad, y al recibir estas ayudas se convierten a su vez en dependientes, ya que de otra forma quedarían siempre excluidas al no poder realizar determinadas funciones, por lo tanto, partiendo de esta visión y adoptando una posición ecléctica, estos autores llegan a la 
conclusión de que las personas con discapacidades siempre serán dependientes en sociedades occidentales, o de otra forma quedarán relegadas a posiciones marginales, con lo cual nunca podrán superar los obstáculos arquitectónicos, sociales, económicos y culturales que existen en la sociedad (34).

Bajo ningún pretexto podemos relegar de la sociedad a las personas con discapacidades, ya que de esta forma correríamos el peligro de perder la memoria colectiva, por lo que las cuestiones como poder, justicia, igualdad, ciudadanía y democracia participativa quedarían en papel mojado para hacer frente a la discapacidad (35). En sentido contrario, Oliver (1990) y Shakespeare (1993), aportan la idea de solidaridad colectiva, a lo que Young (1990) afirma: "Hay igualdad entre los grupos sociales y culturalmente diferenciados, que se respetan mutuamente y se afirman los unos a los otros en sus diferencias" $(36,37)$.

Los estudios sobre discapacidad están evolucionando constantemente, tanto en calidad como en cantidad, por ello no es de extrañar que todas las áreas del conocimiento participen de forma tan determinante para abordar un problema que se muestra de forma evidente en nuestra sociedad. Los estudios en torno a la discapacidad nos muestran cómo se ha constituido esencialmente hoy como un criterio para la distribución de los recursos entre las personas con y sin discapacidad; esta distribución de los recursos, comprendida desde una perspectiva utilitarista, se ve apoyada por Oliver (38).

Existen diferentes estudios de carácter científico que se están desarrollando en torno a la discapacidad, y de ellos no solo destacan los del área de la salud, sino el abordaje de los problemas sociales a los que se enfrentan las personas con discapacidad, los cuales se pueden apreciar en áreas tan distintas pero a su vez tan convergentes como son la psicología, la antropo- 
logía y el derecho o las ciencias de la educación, entre otras, que desde una posición ecléctica se proponen avanzar en el estudio de los temas sociales bajo una perspectiva diferente y convergente al campo de la salud.

Otra de las tendencias con las que cuentan actualmente las personas con discapacidad se refiere a la protección jurídica, que en los últimos años ha experimentado un aumento considerable, para poder proteger a aquellos que se encuentran en una posición más desfavorable en la sociedad. En la actualidad surgen constantemente estudios que abordan el tema de la discapacidad desde un ámbito legal, con el que poder hacer frente desde una perspectiva no solo nacional, sino internacional con motivo de la declaración del año 2003 por parte de la Unión Europea, como «Año de la Discapacidad», mostrando cómo los diferentes organismos internacionales han calado en las normativas nacionales (39).

La sociología de la discapacidad afirma que no existe una única teoría en torno a la discapacidad, ya que son muchos y diversos los temas que se abordan bajo este aspecto temático. Aunque bien es cierto que en estos momentos los estudios sociológicos sobre la discapacidad son bastante limitados, para definir el término discapacidad estos autores recurren a los paradigmas que sustentan las distintas teorías que nos acercarán al funcionalismo biológico, al interaccionismo social y nosotros la completamos con la perspectiva socio-crítica e integramos las tres en la perspectiva de la teoría de sistemas, mostrando en último término llegar a una sinergia entre las tres posturas, donde la complementariedad será el punto de articulación que dará forma a una perspectiva integral (34).

El propósito de esta reflexión consistía en visibilizar algunos aspectos de la salud, la enfermedad y la discapacidad, desde la experiencia humana y no solo desde las implicaciones científicas, a las cuales se dedican las ciencias biomédicas. De esta manera lo importante en esta tematización no eran los 
problemas científicos y tecnológicos de la intervención en salud, sino la manera como el ser humano vive la salud, la enfermedad y la discapacidad, no solo desde su condición biológica, sino desde su ser anímico y su condición intersubjetiva, pero para ellos era necesario cincelar la manera cómo ellos viven la enfermedad. Es propio entonces enunciar algunas conclusiones que brotan de la experiencia humana, entendida esta como: "Verdad es que en cierta manera puede decirse: siempre que se hace experiencia, se hace experiencia de algo, algo está dado y dado sin más, por ejemplo, el árbol que vemos" (27).

Primero, la experiencia de la salud enmarcada en el cuerpo cósico deja huellas que no se pueden borrar, y se constituye como una sombra que acompaña al ser humano en toda su existencia, sin embargo, esta huella en el cuerpo se hace recuerdo y la vivencia de los recuerdos no tiene tanto impacto como las experiencias de los hechos. Es más, entre más tiempo transcurre entre la experiencia en carne y hueso de la patología y el recuerdo que lo trae el presente en la memoria, menos influencia tiene en el ser humano tal experiencia. No es lo mismo vivir la enfermedad que recordarla, la primera puede modificar los hábitos del ser humano, la segunda es más fácil esconderla detrás de la impotencia de las personas.

Segundo, la experiencia de la enfermedad es privada, no sale de la piel de la intimidad de quien la padece, y por consiguiente la experiencia de la salud también lo es; esto implica que la experiencia patológica no es comunicable, y sin embargo las ciencias médicas la comprenden y en esta comprensión han desmembrado el cuerpo, lo dividen con fines metodológicos de la ciencia, con las mejores intenciones, esto es indudable, pero no por ello menos grave, para la concepción del ser humano como un ser integral.

Tercero, el cuerpo en el mundo de la vida se trasciende a sí mismo, y en este escenario la conciencia del cuerpo es asumida, no como entidad fáctica 
sino del cuerpo vivido, como construcción psicológica, no en el sentido positivo de la ciencia, sino como la construcción del sujeto mismo como idea. En esta esfera ya no podemos hablar únicamente del dolor, sino y especialmente del sufrimiento, como perturbación del alma (ánimo). El alma se desparrama por todo el cuerpo, por eso el sufrimiento no se puede localizar en el cuerpo, el sufrimiento es de la totalidad corporal. De esta forma el tiempo y el espacio se abren en el infinito cuando el sujeto se ve acorralado por una enfermedad; el tiempo y espacio se cierran y oprimen de tal manera al sujeto corporal de malas noticias patológicas. En este campo, el cuerpo que en el primer nivel se invisibiliza, aquí se hace presente lleno de luces que delinean la geometría del sufrimiento.

Cuarto, de la conciencia del dolor se pasa a la conciencia del sufrimiento y de este a la angustia, coexiste en el ser humano una manera de amplificarse de lo más particular a lo más universal, el sufrimiento se refleja en el rostro. El rostro salva al ser humano corporal de su soledad, y lo exterioriza hacia los otros. En el rostro se reconocen los padeceres del sujeto y pueden ser, si no sentidos, sí reconocidos por los seres humanos que cohabitan con el sujeto. La experiencia de la enfermedad implica un proceso cultural que está compuesto por hábitos que transitan de generación en generación de tal manera que marca la vida de los seres humanos tanto en su singularidad como en sociedad. En este sentido la experiencia de la patología hay que entenderla desde la conciencia y el cuerpo, pero no independientes sino fusionados como afirma Sartre: "Sería preciso decir, más bien, sirviéndose del verbo existir como de un transitivo que la conciencia existe su cuerpo" $(40,41)$.

Quinto, el tiempo y el espacio en sentido intersubjetivo depende única y exclusivamente de la cultura y de la sociedad, ya no es el tiempo corporal, ni el tiempo psicológico, sino el tiempo de los otros en correlación con mi existencia. En este sentido, la experiencia de la patología, hay que mirarla 
desde esta temporalidad, que generalmente está marcada por símbolos, y fechas especiales, lo mismo que el espacio; ahora pensamos en espacios comunitarios, en espacios compartidos, la enfermedad en estos escenarios cobra nuevos valores.

Sexto, la experiencia de la salud, la enfermedad y la discapacidad a través de la conciencia corporal implica generar en los seres humanos, así se lea redundante, más conciencia; ascender de la conciencia empírica a la conciencia vivencial y de esta a la conciencia intersubjetiva, es el papel de los profesionales en salud, cuando se trata de generar intencionalidad en pos de la calidad humana. La enfermedad como un mal, visto desde la cultura se prolonga cada vez más, crece cada vez en mayores proporciones, como afirma Levinas (30) "El mal engendra el mal y el perdón lo prolonga hasta el infinito".

\section{REFERENCIAS BIBLIOGRÁFICAS}

1. Le BD. Adiós al cuerpo. Una teoría del cuerpo en el extremo contemporáneo, Colonia del Valle: La Cifra. 2007: 26.

2. Scalante, $\mathrm{R}$ de Pablos. La voluntad como deseo consciente: Kuno Fischer entre Spinoza y Nietzsche. Anales del Seminario de historia y filosofía. Universidad de Puerto Rico. 2016; 33(1):148.

3. Belting, H. Antropología de la imagen. Madrid: Editorial Katz. 2007.

4. Boollnow OF. Introducción a la filosofía del conocimiento. La comprensión previa y la experiencia de lo nuevo. Argentina: Amorrortu Editores. 1979.

5. Canguilhem G. Lo normal y lo patológico. Madrid: Siglo Veintiuno Editores. 2005: 12-58.

6. Torrebadella FX. El Arte gimnástico-médico. Del humanismo al renacimiento de la educación física en España. Pecia Complutense. 2014. Año 11. (21): 21-45. 
7. Husserl, E. Investigaciones lógicas (1922) (IL), Morente, M. \& Gaos, J. (trads.). Madrid: Alianza. 1982.

8. Le BD. Sociología del cuerpo. Buenos Aires: Nueva Visión. (2002 (1992)).

9. Díaz Álvarez JM. Conciencia versus cuerpo. Algunas reflexiones sobre una crítica de A. Gurwitsch a Hubert L. Dreyfus. Investigaciones Fenomenológicas, vol. monográfico 2: Cuerpo y alteridad. 2010. Mexico: 212.

10. Feher M. Fragmentos para una historia del cuerpo humano. Parte primera. Madrid: Tauros. Humanidades e historia. 1990.

11. Foucault M. El nacimiento de la clínica Una arqueología de la mirada médica. París: Siglo Veintiuno. 1989.

12. Husserl E. Ideas relativas a una fenomenología pura y una filosofía fenomenológica. Libro segundo. Investigaciones fenomenológicas sobre la Constitución. Universidad Nacional Autónoma de México. México. 1997.

13. Le Breton D. Rostros. Ensayo de Antropología (Traducción de Estela Consigli). Buenos Aires: Letra Viva. 2010.

14. Mainetti JA. «Historia de la ética médica en América Latina», trabajo a publicarse en la segunda edición de la Encyclopedia of Bioethics, en versión traducida al inglés bajo el nombre Medical Ethics, History. V. the Amedcas D. Latin America. Kennedy Institute of Ethics, Georgetown University, USA. 1991.

15. Vanegas JH. Ética: la mejor forma de ser hipócritas. La máscara de la realidad. Universidad Autónoma de Manizales. Manizales Colombia. 2005.

16. Merleau-Ponty M. La fenomenología de la percepción. Barcelona: Planeta-Agostini. 1984.

17. Husserl E. Investigaciones lógicas II. Madrid: Atalaya. 1995.

18. Merleau-Ponty M. El ojo y el espíritu. Barcelona: Paidós. 1986.

19. Merleau-Ponty M. Lo visible y lo invisible. Barcelona: Seix Barral. 1970.

20. Vanegas JH. La conciencia de mi cuerpo en relación con el cuerpo 
extraño y la labor de los profesionales en salud. En: Estética, fenomenología y hermenéutica. 2008, Congreso Colombiano de Filosofía. Universidad de Bogotá Jorge Tadeo Lozano.

21. Vanegas JH. Conciencia e intencionalidad, visión cognitiva y fenomenológica. En: Revista Ánfora año 17, Número 28, enero-junio de 2010. UAM.

22. Le BD. Antropología del cuerpo y modernidad. Buenos Aires: Nueva Visión. 1990.

23. Viveros M, Garay G. Cuerpos, diferencias y desigualdades. Universidad Nacional de Colombia. VIII Congreso de Antropología en Colombia. 1999.

24. Starobinsky J. Monsieur Teste frente al dolor. En: Fragmentos para una historia del cuerpo humano. Parte segunda. Madrid: Tauros. Humanidades e historia. 1991.

25. Onfray M. Teoría del cuerpo enamorado. Por una erótica solar. Valencia, España: Pre-Textos. 2002.

26. Vanegas JH. El cuerpo: el rastro del tiempo. En: Acta Fenomenológica Latinoamericana. Volumen III. Pontificia Universidad Católica del Perú. 2009.

27. Jaramillo MM. Fenomenología de la corporalidad. En: Revista UIS-Humanidades. 1999; 28(2).

28. Vanegas JH, Duque JE. El hechizo de la conciencia: entre la filosofía y la neurobiología. En: Archivos de Medicina. Julio-diciembre de 2016. Universidad de Manizales, 2016; 16(2): 510.

29. Husserl E. Ideas relativas a una fenomenología pura y una filosofía fenomenológica. Libro tercero. La fenomenología y los fundamentos de la ciencia. Universidad Nacional Autónoma de México. México, 2000.

30. Levinas E. Entre nosotros. Ensayo para pensar en otro. Valencia, España: Pre-Textos. 1993.

31. Montoya J. La escritura del cuerpo/el cuerpo de la escritura. Universi- 
dad de Antioquia. Medellín Colombia. 2001.

32. Heidegger M. El ser y el tiempo. Santafé de Bogotá: Fondo de Cultura Económico. 1993.

33. Organización Mundial de la Salud. Clasificación Internacional de Deficiencias, Discapacidad y Minas Valias. CIDDMI. Disponible en http:// usuarios.discapriet.es/ajimenez/Documentos

34. Sissa G. Los cuerpos sutiles. En: Fragmentos para una historia del cuerpo humano. Parte tercera. Madrid: Tauros. Humanidades e historia. 1992.

35. Barnes C. Las teorías de la discapacidad y los orígenes de la opresión de las personas discapacitadas en la sociedad occidental. En L. Barton (Ed.), Discapacidad y sociedad. Madrid: Morata/Fundación Paideia. 1998, 59-76.

36. Andrews, JE, Carnine, DW, Coutinho, MJ, Edgar, EB, Forness, SR, Fuchs, LS, Jordan, D, Kauffman, JM, Patton, JM, Paul, J, Rosell, J, Rueda, R, Schiller, E, Skrtic, M y Wong, J. Salvant les diferències al voltant de l'Educació Especial. Suports. 2001; 5(1): 68-72.

37. Apple. What postmodernist forget: cultural capital and official Knowledge. En: Currículo Studies. 1993; 1(3).

38. Oliver, M. The Politics of disablement. Houndmills: Macmillan Press. 1990.

39. Flórez J. “2003 año Europeo de la Discapacidad” Disponible en http:// www.infonesocio.com/downcan.

40. Shakespeare, T. «Disable people's self organisation: a new social movement? ». En: Disability, Handicap \& Society. 1994.

41. Oliver, M. (1998). ¿Una sociología de la discapacidad o una sociología discapacitada? En: L. Barton (Ed.), Discapacidad y sociedad (pp. 34-58). Madrid: Morata/Fundación Paideia.

\footnotetext{
Cómo citar este capítulo:

Vanegas García JH, Vidarte Claros JA. (2018). La experiencia de la salud, la emfermedad y la discapacidad a travéz de

la conciencia corporal. In Pinillos Patiño Y, Herazo Beltrán Y, Vidarte Claros JA, Crissién Quiroz EM, Suárez Palacio

D, García Puello F, et al. Caracterización de la discapacidad en el distrito de Barranquilla. Una mirada conceptual y experiencial. Barranquilla: Universidad Simón Bolívar, p. 145-177.
} 